\title{
Net Neutrality - A Look at the Future of Internet
}

\author{
Mr. Havish Madhvapaty, Ms. Shiva Goyal \\ Assistant Professor-Marketing (Amity Global Business School, Noida) \\ Assistant Professor - I.T. (Amity Global Business School, Noida)
}

\begin{abstract}
The Internet is an indispensable medium. The success story of Internet has evolved free from complex government regulation. But there is an increasing threat that Internet Service Providers (ISPs) will alter the accessible, open and neutral platform upon which the Internet was founded. Net neutrality might be one of the most discussed, least understood concept in the world of Internet policy. Owing to the fact that there are so many definitions with so many apparently different goals - the net neutrality debate at times seems only about what it is rather than whatit should (or should) not be.

The paper does a status check on the current stand and position on net neutrality. The paper has been written from the vantage point of the United States - where the concept originated and is discussed most vocally. The implications are worldwide though.

In addition to the already bad precedent set in the Netflix vs. Comcast case - where Comcast customers to Netflix faced degraded connection - and Netflix eventually had to relent and pay to Comcast; there are several such signs of a future where Internet might not be free.

The present stand is that in May 2014 Federal Courts Commission (FCC) Chairman Tom Wheeler seemingly is attempting to reclassify and regulate the Internet as a public utility. Lobbyist organizations like NCTA (National Cable and Telecom Association) and CTIA (Cellular Telecom and Internet Association) are also funding consumer groups to rally against a democratic Internet. Then there are organizations like the EFF (Electronic Frontier Foundation) which seek to defend civil liberties in the digital world and are championing the cause of net neutrality.

Internet is the single greatest technology of our time and should not be at the mercy of corporations. It is also noted that these big Internet providers are not targeting content providers but rather end users to pay for the special Quality of Service (QOS).

It is also seen that internet fast-lanes - one of the mostly hotly debated topic today - might be understood. In some form - through the use of Content delivery Network (CDN) - these fast-lanes already exist.

It can be concluded that the problem today is not fast-lanes but undue control over fast speeds. The focus should not be to keep the network neutral but rather to ensure there is increased competition between ISPS - and to promote a vibrant market for fast Internet speeds open to everyone.
\end{abstract}

Key Words:Net neutrality, ISP (Internet Service Providers), Federal Courts Commission (FCC), Open Internet Rules, National Cable and Telecom Association (NCTA), Cellular Telecom and Internet Association (CTIA), Electronic Frontier Foundation (EFF)

\subsection{History of net neutrality}

\section{Introduction}

Since the Internet's inception, it was ensured that there are governing principles in its operation that ensures nondiscrimination requirements in all relevant performance dimensions, which was similar to what traditional telecommunication services such as the telephone network had already been doing.

The roots can be traced in the United States. In 2003, Professors Wu and Lessig pleaded in favor of regulation of network neutrality in an open letter to the Federal Commission for Communications (FCC). ${ }^{1}$ In 2005, the FCC had to face for the first time a network neutrality issue. An Internet Service Provider (ISP) called Madison River Communications had blocked VoIP (Voice over Internet Protocol) traffic to favor the use of its traditional phone lines. The case was settled between the FCC and the ISP, which agreed to pay a fine and end any discriminatory practices in respect of VoIP traffic. ${ }^{2}$

Columbia media law professor Tim Wu used "net neutrality" to explain how the concept of "common carriage" could be applied to the Internet. "Common carriage" is a centuries-old legal concept developed to ensure that the public retain access to fundamental services that use public rights of way. Tim Wu, who helped define and popularize the term, laid out what could go wrong under such rules. He said "This is what one might

\footnotetext{
${ }^{1} \mathrm{http} / / /$ www.arcep.fr/index.php?id=2231\&tx_gspublication_pi1[uidDocument] $=338 \&$

${ }^{2}$ Lawrence Lessig and Tim Wu, Letter to the FCC: ex parte submission CS Docket n02-52, 22 August 2003.
} 
call a net-discrimination rule, and, if enacted, it will profoundly change the Internet as a platform for free speech and small-scale innovation."

Net neutrality is the principle that Internet service providers and governments should treat all Internet traffic the same. This means that ISPs should not block or slow down traffic on their local broadband networks based on individual users or the type of traffic those users are accessing or by the type of service that is sending the content.

The idea is to ensure that consumers can access any legal content they want; while also ensuring that companies using these broadband networks to reach their customers will not have their services interfered with by the companies that control the Internet connections into people's homes.

The term "net neutrality" refers to a bundle of open access principles enforced in a variety of legal and technical ways. According to one common definition, "net neutrality means simply that allInternet content must be treated alike and move at the same speed over the network." ${ }^{\prime 3}$ As used by scholars, lawyers, and engineers, the term "net neutrality" can refer simultaneously to three different understandings. First, the term can address a collection of theoretical "net neutrality principles" - mainly, the principles that we should protect innovation, free speech, and competition on the Internet. ${ }^{4}$ Second, it can encompass the set of legal rules and policies that the FCC enforces, first adopted in the "Internet Policy Statement" and, more recently, in the "Open Internet Rules." ${ }^{, 5}$ Lastly, it can refer to the network protocols and Internet architecture that can direct, on the technical level, how ISPs discriminate among content, services, or applications. Of course, the theoretical, legal, and technical definitions are related in that theoretical net neutrality principles often inform the legal codification and technical execution of net neutrality.

This idea of net neutrality - this cherished idea, even, among Internet entrepreneurs and activists - has a long history, roughly as long as the commercial World Wide Web. It is, Harvard law professor Lawrence Lessig has argued, what makes the Internet special.

He used to call the principle e2e, for end to end: "e2e. Not b2b, or b2c, or $c 2 b$, or b2g, or g2b, but e2e. End to end. The core of the Internet, the core value that defined its power, the core truth that made innovation around it possible, is this e2e," Lessig said in a 1999 talk at Amsterdam, Netherlands. ${ }^{6}$

\subsection{Net Neutrality at FCC}

The U.S. Federal Communications Commission's net neutrality regulations are also known as Open Internet rules. The "Open Internet" is the Internet as we know it. It's open because it uses free, publicly available standards that anyone can access and build to, and it treats all traffic that flows across the network in roughly the same way. The principle of the Open Internet is sometimes referred to as "net neutrality." Under this principle, consumers can make their own choices about what applications and services to use and are free to decide what lawful content they want to access, create, or share with others. This openness promotes competition and enables investment and innovation.

On December 23, 2010, the Commission released the Open Internet Order, which established highlevel rules requiring transparency and prohibiting blocking and unreasonable discrimination to protect Internet openness. The FCC's rules were challenged in federal court, and on January 14, 2014, the United States Court of Appeals for the District of Columbia Circuit affirmed the Commission's authority to regulate broadband Internet access service and upheld the Commission's judgment that Internet openness encourages broadband investment and that its absence could ultimately inhibit broadband deployment. The court upheld the transparency rule, but vacated the no-blocking and no-unreasonable-discrimination rules. The court also invited the FCC to act to preserve a free and open Internet.

A look back at the long history of net neutrality rules at the $\mathrm{FCC}^{7}$ :

February 2004: After many months of debate about the potential for broadband providers to selectively block or slow some Internet traffic, FCC Chairman Michael Powell, a Republican, calls for four Internet freedoms encompassing net neutrality.

August 2005: The FCC, while voting to end regulations requiring incumbent telecommunications carriers to share their DSL broadband connections with competitors, approves an Internet policy statement reflecting Powell's four freedoms. The policy statement, which does not have the force of regulation, says broadband users are entitled to run Web applications and services of their choice and connect their choice of legal devices to the network.

\footnotetext{
${ }^{3} \mathrm{http} / /$ www.washingtonpost.com/wp-dyn/content/article/2006/06/07/ AR2006060702108.html

${ }^{4} \mathrm{http}: / /$ www.cnn.com/2010/OPIN10N/08/05/franken.net.neutralit>1/;

${ }^{5} \mathrm{http}: / /$ www.fcc.gov/openInternet

${ }^{6}$ Full text of lecture accessible on http://cyber.law.harvard.edu/works/lessig/www9.pdf

${ }^{7} \mathrm{http} / /$ www.pcworld.com/article/2048209/net-neutrality-at-the-us-fcc-a-brief-history.html
} 
November 2005: Ed Whitacre, CEO of SBC (soon to be AT\&T), complains to BusinessWeek about companies like Google and Vonage. "Now what they would like to do is use my pipes free, but I ain't(sic) going to let them do that because we have spent this capital and we have to have a return on it."

December 2006: AT\&T pledges to maintain a "neutral network" in exchange for U.S. government approval of its proposed acquisition of BellSouth.

May 2007: Comcast broadband subscribers, including networking expert Robb Topolski, begin to notice slowed connections while using BitTorrent and other peer-to-peer applications. The Associated Press, in October, publishes a report of similar results from Comcast's network. Comcast says its managing network traffic during times of heavy use.

April 2008: FCC Chairman Kevin Martin says Comcast's slowing of peer-to-peer traffic appears to be more widespread than the company had disclosed. In May, the Max Planck Institute for Software Systems finds that Comcast and Cox Communications are slowing BitTorrent traffic at all times of the day, not just during peak traffic. Comcast says BitTorrent can cause traffic peaks at any time of the day.

August 2008: The FCC orders Comcast to stop its "invasive" interference with peer-to-peer traffic on its broadband network and to create a new network management plan.

September 2008: Comcast appeals the FCC's anti-throttling order, arguing that the commission had no hard rules against the company's network management practices.

April 2010: The U.S. Court of Appeals for the District of Columbia Circuit, the same court hearing Verizon's challenge of newer rules, overturns the FCC's Comcast ruling, saying the agency lacks "any statutorily mandated responsibility" to enforce network neutrality rules.

December 2010: After months of discussion, the FCC approves net-neutrality regulations that some consumer and digital rights groups say are weak and full of loopholes.

January 2011: Verizon files a challenge to the net-neutrality rules, saying the FCC doesn't have the authority to enforce them. After the D.C. appeals court tosses out the lawsuit as premature because the rules aren't yet published, Verizon refiles its lawsuit in September 2011. Along the way, mobile provider MetroPCS files a similar lawsuit, and then backs out after it merges T-Mobile USA.

Early 2011 to present: U.S. House of Representatives Republicans try to overturn the FCC's net-neutrality rules, without success.

September 2011: Digital rights group Free Press files a lawsuit challenging the net-neutrality rules as too weak, with the group arguing the FCC shouldn't have allowed weaker protections for mobile broadband users. Free Press later drops the lawsuit.

November 2012: AT\&T reverses its decision to prohibit Apple iPhone and iPad owners from using Apple's FaceTime videoconferencing application unless they buy the carrier's most expensive data plans or are connected to Wi-Fi. The original AT\&T decision to block FaceTime raised net neutrality concerns from consumer and digital rights groups.

Sep 2013:The U.S. Court of Appeals for the District of Columbia Circuit hears arguments in Verizon's appeal of the FCC's net-neutrality rules.

\subsection{Internet Fast Lanes}

\section{Present Stand on Net Neutrality}

A lawsuit before the United States Court of Appeals for the District of Columbia Circuit, argued in September 2013, pitted the Federal Communications Commission (FCC) against Verizon. The verdict in the case, delivered January 2014, struck down the FCC's rules. The outcomes of this, and the government's response, remain unclear. However, in April 2014, the FCC indicated that it would allow companies such as Netflix to pay Internet service providers (ISPs) to provide faster "lanes" that would speed traffic. The Federal Communications Commission voted on May 15, 2014 to consider new net neutrality rules that would allow broadband Internet providers to charge companies like Google or Netflix for faster content delivery. The proposal, put forth by FCC Chairman Tom Wheeler, passed by a three to two vote and opens a 60 -day comment period that will eventually lead to another vote and final ruling later this year.

While the proposal does not finalize any rules, it signifies a step toward paid prioritization, whereby providers like Verizon and Comcast could charge companies for faster streaming or access to so-called "fastlanes." Responding to strong criticism of the pay-for-priority model, Wheeler recently amended the proposal's language to stress that the FCC would not allow "commercially unreasonable" business practices like intentionally blocking or slowing of Internet services for some consumers.

Democratic Commissioner Jessica Rosenworcel, who voted in favor of the rules, expressed some hesitation. "We cannot have a two-tiered Internet, with fast lanes that speed the traffic of the privileged and leave the rest of us lagging behind," she said. 
Wheeler, however, insists that such a division won't happen. "I will not allow the asset of the open Internet to be compromised," he said of his proposal. Wheeler was adamant that the task at hand "is not about whether the Internet must be open, but about how and when we will have rules in place."

A different view says that complaints about fast-lane do not make much sense as today privileged companies like including Google, Facebook, and Netflix - already benefit from what are essentially internet fast lanes, and this has been the case for years. Such web giants - and others - now have direct connections to big ISPs like Comcast and Verizon, and they run dedicated computer servers deep inside these ISPs. In technical lingo, these are known as "peering connections" and "content delivery servers," and they're a vital part of the way the internet works. ${ }^{8}$

Traditionally, ISPs have not charged for interconnection points. They're happy to have Google or Netflix or Akamai or Level 3 servers or routers in their data centers because they speed up service for their customers and reduce the amount of traffic that has to flow out of their network. One could look at these arrangements as fast lanes - but because ISPs have treated their networks as an open marketplace and delivered real value to consumers and businesses, they're not the kind of thing that the FCC should be discouraging.

The problem today isn't the fast lanes. The problem is whether the ISPs will grow so large that they have undue control over the market for fast speeds - whether they can independently decide who gets access to what connection at what price. "The question is which kinds of fast lanes are problematic and which kinds are not," says Marvin Ammori, a lawyer and net neutrality advocate.

\subsection{The Netflix vs. Comcast Case}

Netflix and Comcast reached an agreement earlier this year in 2014, in which the video-streaming company agreed to pay Comcast for direct access to its broadband network (aka a fast-lane setup). Before the agreement, Netflix wanted to connect to Comcast's broadband network free of charge. It didn't want to pay for a broadband/speedier fast lane. The cable giant sought compensation for the heavy traffic though, arguing it was expensive to deliver Internet video.

The story is that as Netflix had grown - an argument over who should pay for the increasing loads - the broadband provider or Netflix - had emerged. In the meantime, Netflix has been buying its bandwidth from a company called Cogent, which acts as the middle man between Netflix and Comcast or Verizon, which in turn deliver the stream to consumers. That deal did not work out well.

As the debate heated up, Netflix suggested Comcast customers were experiencing their connections to Netflix degraded. Netflix released data, for instance, that showed the average Netflix streaming speed declined 27 percent since the debate started - as shown in Exhibit 1. In other words, it looked like Comcast was punishing consumers because Netflix was refusing to pay a fast-lane premium.

Exhibit 1: \% change in Netflix download speed since Jan. 2013, by I.S.P.

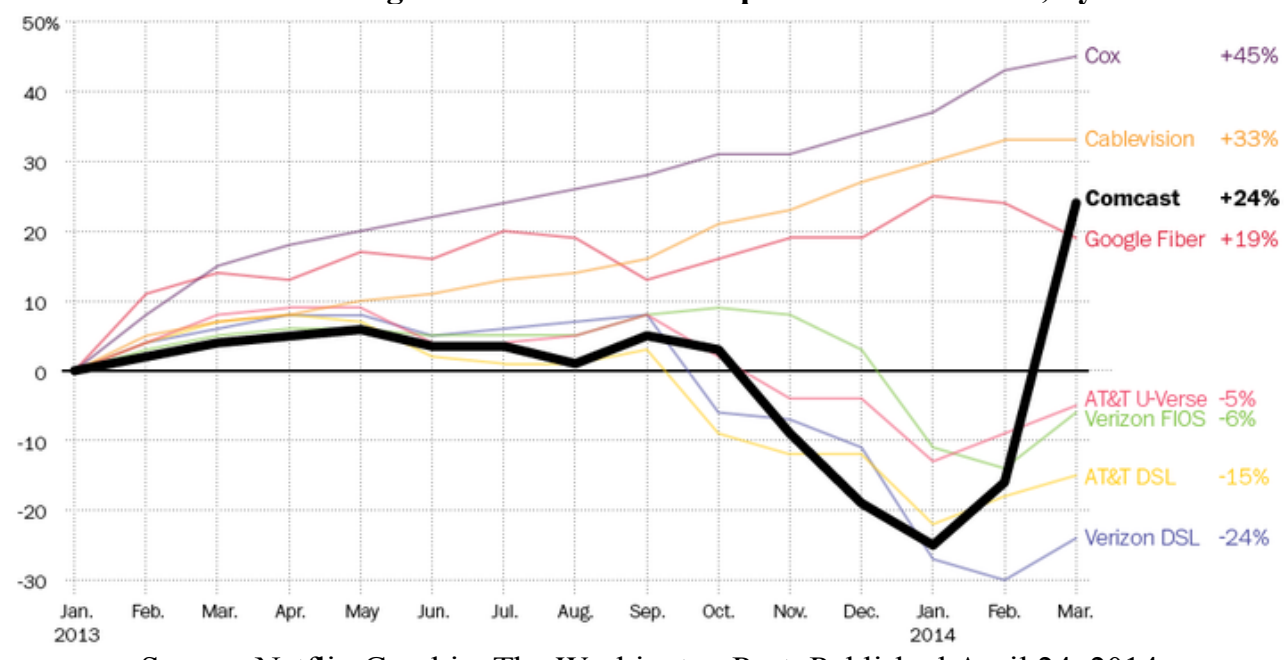

Source: Netflix Graphic: The Washington Post, Published April 24, 2014

When Netflix and Comcast finally came to an agreement (called paid peering), the details, which involved Netflix connecting directly to Comcast's network instead of going through intermediaries, were announced less than two weeks after Comcast revealed a $\$ 45$ billion deal for Time Warner Cable. The merger

\footnotetext{
${ }^{8} \mathrm{http}: / /$ www.wired.com/2014/06/net_neutrality_missing/
} 
would basically reduce competition in the market even further and create a cable kingdom serving 33 million customers across the US.

\subsection{Money Battle on Net Neutrality}

The Sunlight Foundation recently published a series of graphics showing lobbyist spending from companies that support and oppose net neutrality. From 2003 to 2013, anti-net neutrality groups issued nearly three times as many lobbying reports mentioning net neutrality as those that support it, like AOL, Google, and Microsoft. Verizon and AT\&T alone each issued 119 reports, while Google issued less than 25.

Exhibit 2 mentions the number of lobbying reports mentioning net neutrality.

Exhibit 2: Lobbying Reports mentioning net neutrality

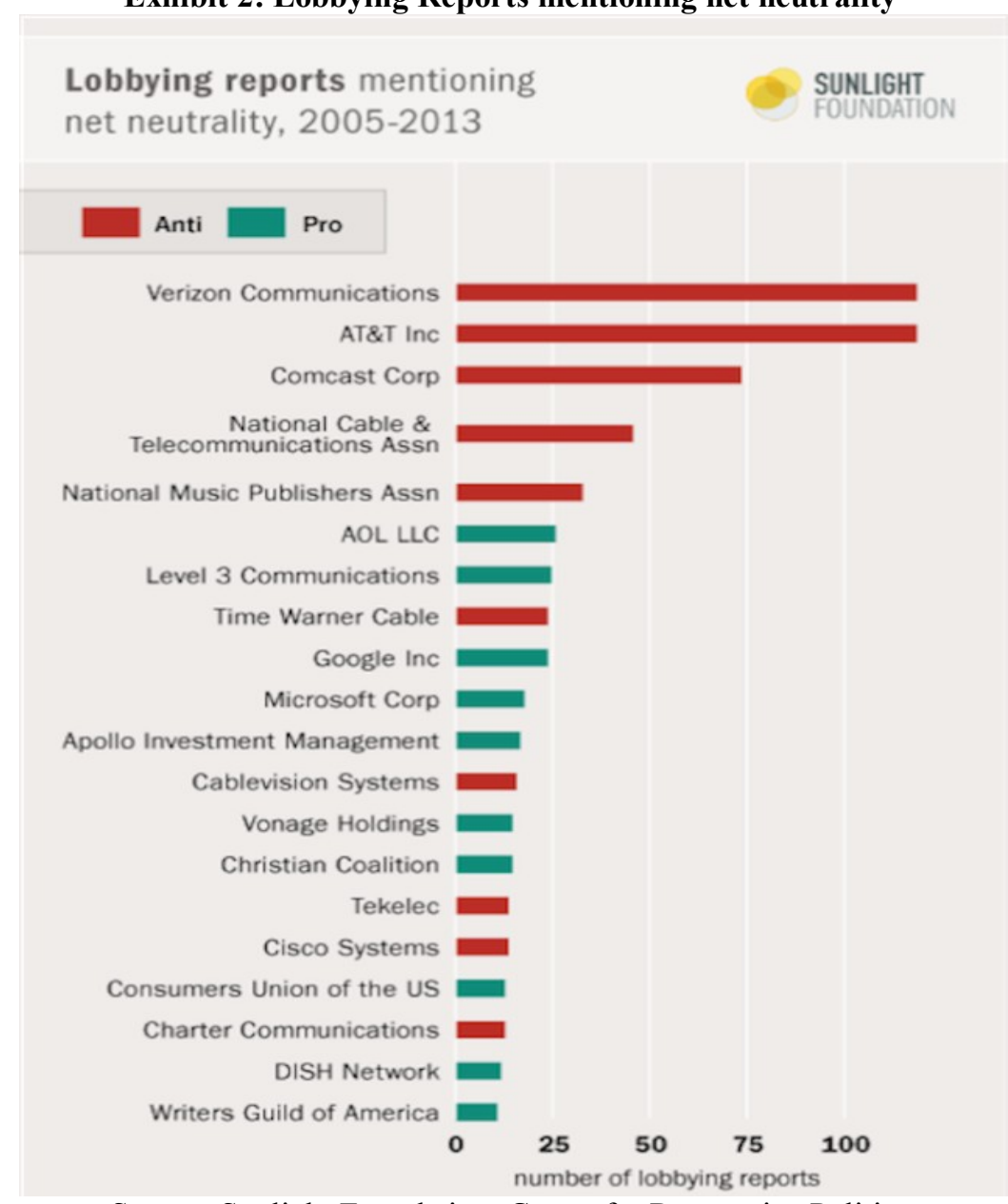

Source: Sunlight Foundation, Center for Responsive Politics

What is of worrying concern is the fact that consumer groups that seemingly rally against democratic Internet are secretly funded by lobbyist organizations. Broadband of America - a coalition of independent advocacy groups are funded by NCTA, the lobbyist organization for big cable - and American Consumer Institute -an anti-net neutrality group gets funding from CTIA - which represents American wireless industry And while it might not be illegal to donate money to consumer groups - or illegal to speak against net neutrality; the method employed here of astroturfing is not in good taste.

\subsection{Agencies supporting Net Neutrality}

Concerned Internet users want to make sure that the FCC and Congress hear them when it comes to keeping the Internet open and free.

Digital-rights advocacy group Free Press, other groups such as MoveOn.org, and mobile operator CREDO, which also has a social activist arm, have organized protests and phone and online campaigns to get the attention of regulators and elected officials in Washington, D.C.

There are also organizations like the Electronic Frontier Foundation. As mentioned on the website: The Electronic Frontier Foundation is the leading nonprofit organization defending civil liberties in the digital world. 
Founded in 1990, EFF champions user privacy, free expression, and innovation through impact litigation, policy analysis, grassroots activism, and technology development. ${ }^{9}$ Other such organizations include Free Press; Moveon.org; ACLU (American Civil Liberties Union); Common Cause; Fight for the Future etc.

Sensing that the FCC was likely caving to the same pressures from deep-pocketed broadband companies, net neutrality activists are rallying support among the public. Organizations like CREDO have started phone and online petitions. Nearly 310,000 people have signed CREDO's online petition. And since its efforts began, CREDO said, more than 1,000 phone calls have been made to the FCC; more than 3,300 calls have been made to US senators, and more than 1,400 to US representatives.

In May 2014 - a sizable coalition consisting technology companies took a stand in favor of net neutrality in the form of a letter to the Federal Communications Commission. The group, led by giants including Amazon, eBay, Facebook, Google, Microsoft, Netflix, Twitter, and Yahoo, challenges the proposal of FCC that threatens net neutrality.

While the letter does not explicitly mention a course of action - like calling on the FCC to regulate Internetservice providers as utilities - the coalition strongly espouses the benefits of an open Internet. "The Commission's long-standing commitment and actions undertaken to protect the open Internet are a central reason why the Internet remains an engine of entrepreneurship and economic growth," the group writes. "This Commission should take the necessary steps to ensure that the Internet remains an open platform for speech and commerce so that America continues to lead the world in technology markets."

The letter marks a first time some influential tech companies, like Amazon, have formally expressed a stance on net neutrality regulations since news of the FCC proposal broke on April 23rd. The letter signifies that technology companies have found a united front in calling for open Internet rules that preserve the key nondiscrimination principle of net neutrality.

\section{Conclusion}

1. It is evident by the Netflix and Comcast agreement that Internet service providers can pick who gets a fastlane connection and at what price. There is nothing to stop them. There is also no definiteInternet rules to outline what is fair or not fair, meaning Internet service providers could conceivably make the two-tier setup (where the rich get fast Internet and the poor get slow Internet) a standard practice.

2. There is hardly any competition among Internet service providers. A broadband study claimed that 96 per cent of Americans have access to two or fewer Internet providers. This new-age monopoly does not encourage market competition. This in fact makes them grow larger and consequently dictate how fast Internet will cost certain companies.

3. If FCC turns its proposed rules into policy, startups that can't even afford lobbyists in the first place stand to lose out.

4. That desire by Internet Service Providers to turn the open Internet into a space where they get to decide who succeeds and who fails (and collect their toll in the process) is exactly what regulation of broadband networks has always been about. The basic rule that the company that connects you to the Internet must treat all of your traffic equally has been in place in some form since 2005 .

5. Some net neutrality advocates applauded the fact that the FCC's proposal leaves open a window for the commission to reclassify broadband providers, which would allow the FCC to regulate them as it does other telecom services. However, such a move is widely considered the nuclear option - reclassification would instantly trigger a maelstrom of legal and political fighting. BigInternet service providers such as Comcast and AT\&T wrote a letter to the commission arguing that reclassification would severely damage their business model and lead to less innovation, less investment in infrastructure and job losses.

6. Allowing ISPs to pick winners and losers online would be a change of course, and a big blow to the openness of the Internet.

7. The open stand taken by coalition of technology companies is a positive sign. A free and open Internet is the single greatest technology of our time, and control should not be at the mercy of corporations. A free and open Internet stimulates ISP competition; helps prevent unfair pricing practices; promotes innovation; promotes the spread of ideas; drives entrepreneurship; and protects freedom of speech.

8. There are astroturfing campaigns that seek to fund consumer groups to rally against a democratic Internet. This is of huge concern.

9. As far as 'fast lanes' are concerned - plenty of websites, applications and ideas will not be able to afford to pay to get into the fast lane; and without a push from these innovative services, it is less likely that our Internet infrastructure will feel pressured to improve in the same way. That means a slowing of innovation in the network itself and a gradual freeze of the Internet at 2014 levels. Everyone with a connection can

\footnotetext{
${ }^{9}$ https://www.eff.org/
} 
access the real Internet today. Tomorrow, we could easily see a widening of the digital divide, where entire communities are left out of the fast lane altogether.

10. An alternate view is that internet fast-lanes already exist - and that it should be ensured that there is increased competition among ISPs.

\section{References}

[1]. ARCEP (2012): "Report to Parliament and the Government on Net Neutrality", http://www.arcep.fr/uploads/tx_gspublication/rapport-parlement-net-neutrality-sept2012-ENG.pdf

[2]. ARCEP (2010): "Internet and network neutrality", hrttp://www.arcep.fr/uploads/tx_gspublication/net-neutralite-orientationssept2010-eng.pdf

[3]. Cave, M., \&Crocioni, P. (2007). Does Europe Need Network Neutrality Rules? International Journal of Communication [Online] 1:1. Available: http://ijoc.org/ojs/index.php/ijoc/article/view/157

[4]. Crandall, Robert (2005) Competition and Chaos, Brookings Institution Press: Washington, D.C. Clark, D. (2007).Network Neutrality: Words of Power and 800-Pound Gorillas. International Journal of Communication [Online] 1:1. Available: http://ijoc.org/ojs/index.php/ijoc/article/view/158/83

[5]. EC (2001).The Development of Broadband Access Platforms in Europe: Technologies, Services, Markets, Full Report, BDRC Ltd for European Commission.

[6]. EC (2001).The Development of Broadband Access Platforms in Europe: Technologies, Services, Markets, Full Report, BDRC Ltd for European Commission.

[7]. http://www.broadband.gr/content/modules/downloads/Report_Broadband_Access_in_Eur ope.pdf

[8]. Eijk, N. van (2011). About Network Neutrality 1.0, 2.0, 3.0 and 4.0. Computers \& Law Magazine, 21(6), 1-4.

[9]. Eijk, N. van (2012). Net Neutrality and Audiovisual Services. In: Price, M., Verhulst, S. \& Morgan, L. (Eds.), Routledge Handbook of Media Law, Routledge, 523-538.

[10]. Federal Communications Commission (2010): "Preserving the open Internet", http://hraunfoss.fec.gov/edocs_public/attachmatch/FCC-10-201A1.pdf

[11]. Merrill Brown and Caroline E. Mayer, U.S. Ends Antitrust Suits Against AT\&T, IBM, The Washington Post Jan 9, 1982.

[12]. Mueller, M. (2002) Ruling the root: Internet governance and the taming of cyberspace. Cambridge, MA: MIT Press.

[13]. NPT (2009): "Network neutrality - Guidelines for Internet neutrality“, http://eng.npt.no/ikbViewer/Content/109604/Guidelines\%20for\%20network\%20neutrality.pdf

[14]. Rochet, J.C. and J. Tirole (2006) Two-Sided Markets: A Progress Report. RAND Journal of Economics, 37: 645-667.

[15]. Wu, T. (2003) Network neutrality, broadband discrimination. Journal of Telecommunications and High Technology Law, $2,141$.

[16]. Wu, T. (2006) The World Trade Law of Internet Filtering. SSRN Electronic paper collection, http://papers.ssrn.com/sol3/papers.cfm?abstract_id $=882459$

[17]. Wu, T. (2007). Wireless Carterfone. International Journal of Communication, [Online] 1:1. 389, Available: http://ssrn.com/abstract $=962027$ 